\title{
O FINANCIAMENTO DO ENSINO MÉDIO NO BRASIL: DE UMA ESCOLA BOA PARA POUCOS À MASSIFICAÇÃO BARATA DA REDE PÚBLICA
}

\author{
Jose Marcelino de Rezende Pinto* \\ NELSON CARDOSO AMARAL ${ }^{* *}$ \\ JoRgE ABRAHÃo DE CASTRO***
}

\begin{abstract}
RESUMO: Este artigo procura fazer um levantamento dos recursos públicos que são destinados ao ensino médio no Brasil. Em particular, são analisados os gastos estaduais que respondem por $82 \%$ das matrículas $(95 \%$ da rede pública). Além disso, são analisados os gastos federais para o setor, em especial, da rede federal de educação profissional técnica, que, embora pequena, oferece um ensino claramente de qualidade. É feita também uma estimativa dos recursos públicos que são destinados à formação profissional pela via do Sistema S. Finalmente, no contexto das discussões do Plano Nacional de Educação 2011-2020, busca-se aquilatar os recursos necessários para o financiamento de um ensino médio integrado e de qualidade.
\end{abstract}

Palavras-chave: Financiamento do ensino médio. Ensino médio de qualidade. Gastos por aluno no ensino médio.

\section{SECONdARY EDUCATION FINANCING IN BRAZIL: \\ FROM A GOOD SCHOOL FOR FEW TO A CHEAP, MASS PUBLIC ONE}

\begin{abstract}
This paper surveys the amount of public funds allocated to secondary schools in Brazil. It analyzes more particularly state expenditures, which account for $82 \%$ of enrolments ( $95 \%$ of the public network). It also explores federal spending for its vocational technical school network, which, albeit small, actually offers quality education. The authors also estimate the public funds spent in vocational training via system S. Finally, in the framework of the discussions of the 2011-2020 National Education Plan, they try to calculate the resources needed to finance quality, integrated secondary education.
\end{abstract}

Key words: Financing of secondary education. High school quality. Spending per pupil in secondary education.

\footnotetext{
* $\quad$ Doutor em Educação e professor associado da Faculdade de Filosofia, Ciências e Letras (campus de Ribeirão Preto) da Universidade de São Paulo (USP). E-mail: jmrpinto@ffclrp.usp.br

** Doutor em Educação e professor associado II (aposentado) da Universidade Federal de Goiás (UFG). E-mail: nelsoncardosoamaral@gmail.com

*** Doutor em Ciência Econômica e pesquisador associado ao Instituto de Pesquisa Econômica Aplicada (IPEA). E-mail: jorge.abrahao@globo.com
} 
FinANCEMENT des Lycées au BRÉsil: D'une bonNe ÉCOle POUR PEU À LA MASSIFICATION BON MARCHÉ DE L'ÉCOLE PUBLIQUE

RÉSUMÉ: Cet article étudie les investissements publics destinés aux écoles au Brésil. Il analyse plus particulièrement les dépenses des états, qui répondent pour $82 \%$ inscriptions (95\% du réseau public). Il examine en outre le budget fédéral pour les écoles techniques professionnelles, lesquelles, bien que peu nombreuses, offrent une éducation de qualité. Les fonds publics destinés à la formation professionnelle via Système $S$ sont également analysés. Finalement, dans le cadre des discussions pour le Plan d'éducation nationale 2011-2020, il calcule les ressources nécessaires pour financer un lycée intégré de qualité.

Mots-clés: Financement des lycées. Lycées de qualité. Dépenses par élève pour les lycées.

\section{Introdução}

S e olharmos para a nossa história, veremos que durante cerca de 460 anos o ensino médio viveu sob controle do setor privado. No início eram os colégios dos jesuítas, depois vieram outras ordens religiosas, ocupando o espaço liberado com a expulsão destes em 1759. Estes estabelecimentos funcionavam como centros de formação de quadros religiosos (seminários), mas também como cursos preparatórios para os filhos da elite local que desejavam continuar seus estudos em Portugal (Romanelli, 1985). Um primeiro arremedo de política pública para o setor veio com a introdução das aulas régias em fins do século XVıII, mas estas não se constituíam em um sistema orgânico de formação, já que se configuravam em aulas avulsas (Latim, Grego, Retórica, Filosofia, entre outras), com professores mal preparados indicados mais por critérios políticos que por competência, vitalícios no cargo (que muitas vezes sublocavam o direito de lecionar) e mal remunerados, uma vez que os recursos para manter o sistema advinham do subsídio literário, um tributo que incidia sobre a venda de carne nos açougues e de aguardente (Melchior, 1987).

Com a promulgação do Ato Adicional de 1834, o ensino médio, juntamente com o fundamental, passou à responsabilidade das províncias, ficando o governo central responsável apenas pela educação superior e pelo ensino básico a ser oferecido no município da Corte. O máximo de esforço a que o governo imperial chegou foi à criação, em 1838, do Colégio Pedro II, no Rio de Janeiro, organizado em sistema seriado com o objetivo de servir de modelo para os demais estabelecimentos. Isto pouco aconteceu porque somente os alunos que cursassem o Pedro II estariam isentos dos exames parcelados (realizados por disciplina) para ingresso no ensino superior. A legislação que instituiu estes exames só foi extinta em 1930. Este sistema deu ao nosso ensino secundário um caráter predominantemente propedêutico e de desarticulação entre as disciplinas, situação que predomina até hoje. 
Com a entrada no século $\mathrm{xx}$, os antigos seminários foram dando lugar aos grandes colégios, também confessionais, onde pontuavam as Congregações Maristas, os irmãos e irmãs Beneditinos, os Colégios do Sion; mais uma vez, os Jesuítas, e tanto outros que marcaram, muitas vezes fisicamente, boa parte da memória (e da pele) de nossa elite dirigente. Não é preciso dizer que todos eram pagos, embora também possuíssem geralmente mecanismos como bolsas de estudo para alunos pobres, forma pela qual buscavam sugerir um caráter filantrópico e escapar à tributação, como, aliás, ocorre até hoje.

Com a introdução do princípio da vinculação para a educação de um percentual mínimo da receita de impostos, pela Constituição Federal de 1934 (revogado na de 1937 e depois retomado na de 1946), e com o grande crescimento econômico que marca o país nas décadas de 1940 e 1950, vemos surgir os grandes ginásios estaduais, estabelecimentos construídos com projetos arquitetônicos adequados, bem equipados com laboratórios, bibliotecas, auditórios e outros recursos didáticos, muitos dos quais ainda sobrevivem, deixando à vista o contraste com os padrões atuais de atendimento. Contudo, é bom alertar que, embora oferecessem boas condições de ensino e de trabalho, estas escolas públicas possuíam um caráter extremamente elitista e seletivo, tanto pela forma de ingresso (geralmente através de exames) quanto de progressão. Além disso, tratava-se de escola diurna, em muitos casos, de tempo integral, excluindo, portanto, o aluno trabalhador. Por fim, há sempre que ressaltar que a maior parte das matrículas continuava em mãos do setor privado (Pinto, 2004).

Outra observação importante é que, neste período, o ensino obrigatório correspondia a, apenas, quatro anos, compondo o antigo primário. Os atuais anos finais do ensino fundamental compunham o ginásio, correspondente ao primeiro ciclo da escola secundária que ainda possuía um segundo ciclo de três anos de duração. Paralelamente, havia também uma rede de ensino profissionalizante que, como dizia explicitamente a Carta de 1937, destinava-se "às classes menos favorecidas".

Esta organização só foi modificada em 1971, com a Lei n. 5.692, que acoplou o primário ao ginásio, criando o ensino de $1^{\circ}$ grau, hoje ensino fundamental, obrigatório e com oito anos de duração, e o ensino de $2^{\circ}$ grau, atual ensino médio, com três anos de extensão. Esta alteração na organização do ensino secundário traria mudanças profundas nos anos seguintes. De um lado, ele foi transformado em compulsoriamente profissionalizante, com forte impacto em sua qualidade, uma vez que as escolas da rede de $2 \underline{0}$ grau não possuíam nem equipamentos nem professores habilitados a oferecer formação profissional em condições adequadas. De outro, com o aumento da obrigatoriedade para oito anos, o Estado se viu compelido a ampliar a oferta de vagas, e isto exatamente em plena ditadura militar, um período em que os gastos com educação atingiam seus patamares mais baixos, situação 
decorrente, entre outras coisas, da retirada da vinculação constitucional de recursos para educação na Constituição de 1967. O resultado foi uma expansão a baixo custo, multiplicando-se os turnos escolares e achatando-se os salários, com prédios precários, professores mal preparados e desmotivados, lançando as raízes de nossa atual escola de massas e para as massas, em oposição às escolas da elite. Neste último segmento, mudanças radicais também foram observadas, com as antigas escolas confessionais de formação mais centrada nas humanidades dando lugar às modernas empresas de ensino, guiadas pelas leis de mercado e que se preocupam tão somente em preparar seus alunos para o ingresso na educação superior.

A tabela a seguir apresenta uma síntese dessa transformação, considerando a nova situação criada a partir de 1971.

\section{Tabela 1}

Evolução da matrícula do ensino médio por tipo de rede (1971-2010)

\begin{tabular}{|c|r|r|r|c|}
\hline Ano & $\begin{array}{c}\text { Particular } \\
(\times 1.000)\end{array}$ & $\begin{array}{c}\text { Público } \\
(\times 1.000)\end{array}$ & $\begin{array}{c}\text { Total } \\
(\times 1.000)\end{array}$ & $\begin{array}{c}\text { Público/Total } \\
(\%)\end{array}$ \\
\hline 1971 & 487 & 632 & 1.119 & 56 \\
\hline 1975 & 877 & 1.059 & 1.936 & 55 \\
\hline 1980 & 1.311 & 1.508 & 2.819 & 53 \\
\hline 1991 & 1.019 & 2.754 & 3.773 & 73 \\
\hline 1996 & 1.177 & 4.562 & 5.739 & 79 \\
\hline 2000 & 1.153 & 7.040 & 8.193 & 86 \\
\hline 2004 & 1.111 & 8.058 & 9.169 & 88 \\
\hline 2010 & 988 & 7.370 & 8.358 & 88 \\
\hline
\end{tabular}

Fonte: Censo escolar (1971-2010).

Os dados apontam para impressionante expansão da matrícula no período, puxada, essencialmente, pelo crescimento da rede pública. As matrículas no setor público cresceram 11,7 vezes no período. O setor privado, por sua vez, apresentou uma expansão de 169\% no período 1971 a 1980, iniciando, a partir daí, um processo de queda seguido de estagnação, de tal forma que, em 2010, a matrícula no setor representou $75 \%$ do valor obtido em 1980 . No nosso entendimento, esse fato relaciona-se, de um lado, ao reduzido tamanho da classe média do país, que pouco cresceu, uma vez que a escolha da rede privada, no Brasil, está diretamente associada à renda familiar e, por outro lado, à redução do número de filhos, que se deu, mais acentuadamente, nos estratos econômicos de maior renda. Esse fato explica também por que o setor privado tem investido cada vez mais na educação superior (onde a presença 
do setor público é ainda muito pequena), bem como na venda de material didático e assessoria para as redes públicas de ensino da educação básica, como mostram Adrião et al. (2009).

\section{Os gastos com ensino médio no Brasil: um mistério a ser decifrado}

Por incrível que possa parecer, o maior desafio de um artigo como esse - que tem como objetivo analisar os gastos do ensino médio no Brasil - é, precisamente, descobrir quais são, efetivamente, os gastos com ensino médio no Brasil. Isso porque, até hoje, não obstante os avanços feitos pelos órgãos públicos no levantamento e disseminação de informações de gastos educacionais, ainda não existe uma confiabilidade plena nos dados disponibilizados. Talvez seja essa a primeira constatação deste trabalho. Portanto, antes de qualquer análise, será feito um esforço para se obter uma primeira aproximação dos gastos efetivamente realizados nesta etapa de ensino.

Como ponto de partida, vamos analisar de que forma se distribuem as matrículas no ensino médio no Brasil entre as dependências administrativas. Os dados para 2010 são apresentados na tabela seguinte:

\section{Tabela 2}

Matrícula no ensino médio por dependência administrativa - 2010

$(\mathrm{X} 1.000)$

\begin{tabular}{|c|c|c|c|}
\hline Dep. Administrativa & Ensino médio regular & EJA & $\begin{array}{c}\text { Ed. Profissional } \\
\text { exclusiva* }^{*}\end{array}$ \\
\hline Federal & 102 & 14 & 89 \\
\hline Estadual & 7.177 & 1.274 & 290 \\
\hline Municipal & 91 & 46 & 23 \\
\hline Privada & 988 & 93 & 523 \\
\hline Total & 8.358 & 1.427 & 925 \\
\hline
\end{tabular}

Obs: * Não inclui as matrículas da educação profissional integrada ao ensino médio, a qual está incluída no ensino médio regular.

Fonte: Censo 2010 - Resumo técnico (INEP).

Os dados mostram o predomínio da rede estadual na oferta do ensino médio, com exceção da educação profissional exclusiva, na qual predomina o setor privado. Como aponta Oliveira (2009), esta privatização da educação profissional é coincidente com as recomendações das agências internacionais de financiamento. Considerando as diferentes modalidades apresentadas nesta tabela, constata-se que a 
rede estadual responde por $82 \%$ das matrículas, seguida pela privada (com $15 \%$ ), pela federal (com $2 \%$ ), ficando a municipal com $1 \%$. Considerando apenas o ensino médio regular (que inclui a educação profissional integrada), os percentuais são, respectivamente, $86 \%$ (estadual), $12 \%$ (privada), $1 \%$ (federal) e 1\% (municipal).

Como o foco deste trabalho é analisar os gastos na rede pública, nossa principal atenção deve ser, portanto, com a rede estadual. Analisaremos também a rede federal, considerando sua importância e sua qualidade, em especial no ensino médio integrado à educação profissional. Não analisaremos a rede municipal, tendo em vista a baixa qualidade dos dados, sua declinante participação na oferta, em especial após o Fundo de Manutenção e Desenvolvimento do Ensino Fundamental e de Valorização do Magistério (FUNDEF) e, principalmente, porque, nos termos da Constituição Federal, essa não é sua etapa de atuação prioritária. Discutiremos também a questão dos recursos públicos que são administrados pelo setor empresarial, por meio do chamado "Sistema S".

\section{Os gastos dos estados com o ensino médio}

Considerando que as redes estaduais respondem por mais de $96 \%$ das matrículas públicas no ensino médio, um olhar cuidadoso sobre os seus gastos é o caminho mais indicado para se obter os investimentos nesta etapa. Como fonte de dados, será utilizado o Sistema de Informações sobre Orçamentos Públicos em Educação (sıOPE), que foi criado em 2004, tendo por referência o Sistema de Informações sobre Orçamentos Públicos em Saúde (sıops), do Ministério da Saúde, que existe desde 1993. O siope é gerenciado pelo Fundo Nacional de Desenvolvimento da Educação (FNDE), autarquia vinculada ao Ministério da Educação (MEC) através de um sistema eletrônico que é alimentado pelos estados, Distrito Federal e municípios com informações sobre receitas e despesas em educação. Não obstante o inegável avanço que representa a implantação do sıope, os dados do sistema devem ser analisados com cautela. Em primeiro lugar, porque, sendo preenchidos pelos entes federados, as receitas e despesas ali contabilizadas nem sempre representam os gastos efetivos em manutenção e desenvolvimento do ensino, como tem mostrado, de forma sistemática, o pesquisador Nicholas Davies (ver, por exemplo, Davies, 2010). A segunda limitação refere-se à ineficiência na contabilização das despesas educacionais nas respectivas rubricas e etapas de ensino a que se referem. Em especial com o FUNDEF, que estabelecia que $60 \%$ das despesas deveriam ser destinadas ao ensino fundamental, criou-se o mau hábito de contabilizar boa parte dos gastos das secretarias de educação no ensino fundamental. Isso afeta em particular os gastos no ensino médio, porque geralmente os professores que lecionam nesta etapa o fazem também nos anos finais do ensino fundamental; sendo comum a contabilização de seus salários neste último. 
A tabela a seguir, elaborada a partir dos dados do siope para o ano de 2008, dá uma clara amostra das dificuldades de se tomar como corretos os dados na forma apresentada por essa base.

\section{Tabela 3}

Gastos por aluno nas redes estaduais, comparados com o valor-aluno do FUNDEB e com as matrículas -2008

\begin{tabular}{|c|c|c|c|c|c|}
\hline & $\begin{array}{l}\text { (2) } \\
\text { Gasto/aluno no } \\
\text { ensino médio } \\
\text { R\$ }\end{array}$ & $\begin{array}{c}\text { (3) } \\
\text { Gasto/aluno na } \\
\text { educação básica } \\
\text { R\$ }\end{array}$ & $\begin{array}{c}(4) \\
\text { Valor FUNDEB } \\
\text { ensino médio } \\
\text { urbano } \\
\text { R\$ }\end{array}$ & $\begin{array}{c}\text { (5) } \\
\text { Participação EM } \\
\text { na matricula } \\
\%\end{array}$ & $\begin{array}{c}(6) \\
\text { Participação EM } \\
\text { na despesa da } \\
\text { educação básica } \\
\%\end{array}$ \\
\hline $\mathrm{AC}$ & 74 & 3.298 & 2.369 & $26 \%$ & $0,4 \%$ \\
\hline $\mathrm{AL}$ & 982 & 2.161 & 1.365 & $43 \%$ & $18 \%$ \\
\hline $\mathrm{AP}$ & 3.131 & 3.566 & 2.468 & $26 \%$ & $20 \%$ \\
\hline $\mathrm{AM}$ & 1.040 & 2.825 & 2.468 & $32 \%$ & $11 \%$ \\
\hline BA & 1.792 & 2.060 & 1.365 & $54 \%$ & $38 \%$ \\
\hline $\mathrm{CE}$ & 379 & 2.269 & 1.365 & $68 \%$ & $11 \%$ \\
\hline $\mathrm{DF}$ & 5.126 & 4.270 & 2.256 & $20 \%$ & $15 \%$ \\
\hline ES & 1.789 & 3.350 & 2.688 & $47 \%$ & $21 \%$ \\
\hline GO & 3.081 & 2.527 & 1.676 & $43 \%$ & $45 \%$ \\
\hline MA & 373 & 1.933 & 1.365 & $57 \%$ & $10 \%$ \\
\hline MT & 19 & 2.261 & 1.892 & $38 \%$ & $0,3 \%$ \\
\hline MS & 1.981 & 2.896 & 2.146 & $36 \%$ & $18 \%$ \\
\hline MG & 1.179 & 2.736 & 1.701 & $33 \%$ & $13 \%$ \\
\hline PA & 1.607 & 1.607 & 1.365 & $48 \%$ & $43 \%$ \\
\hline $\mathrm{PB}$ & 674 & 1.370 & 1.365 & $36 \%$ & $15 \%$ \\
\hline $\mathrm{PR}$ & 2.483 & 2.295 & 1.621 & $37 \%$ & $34 \%$ \\
\hline PE & 952 & 1.966 & 1.365 & $45 \%$ & $20 \%$ \\
\hline PI & 1.471 & 1.761 & 1.365 & $50 \%$ & $41 \%$ \\
\hline $\mathrm{RJ}$ & 821 & 3.198 & 1.615 & $49 \%$ & $11 \%$ \\
\hline $\mathrm{RN}$ & 1.444 & 2.257 & 1.599 & $41 \%$ & $25 \%$ \\
\hline RS & 1.725 & 2.256 & 2.021 & $33 \%$ & $23 \%$ \\
\hline RO & 1.870 & 2.428 & 1.846 & $32 \%$ & $17 \%$ \\
\hline $\mathrm{RR}$ & 3.394 & 4.384 & 3.087 & $26 \%$ & $7 \%$ \\
\hline SC & 1.304 & 2.873 & 1.877 & $34 \%$ & $14 \%$ \\
\hline SP & 1.834 & 3.078 & 2.468 & $38 \%$ & $18 \%$ \\
\hline $\mathrm{SE}$ & 3.442 & 2.428 & 1.704 & $37 \%$ & $44 \%$ \\
\hline TO & 1.797 & 2.886 & 2.061 & $33 \%$ & $18 \%$ \\
\hline Brasil & 1.512 & 2.650 & - & $40 \%$ & $20 \%$ \\
\hline
\end{tabular}

Fonte: SIOPE e FNDE. 
Os dados que se encontram na coluna 2 da tabela foram obtidos a partir da divisão dos gastos indicados nas planilhas do siope pelos estados como tendo sido realizados no ensino médio, pelo número de alunos nesta etapa da educação básica. Um rápido olhar em seus valores indica a presença de um subdimensionamento nos montantes declarados como gastos/aluno no ensino médio, com exceção do Distrito Federal, Goiás, Pará, Paraná, Roraima e Sergipe. Na média do país, o gasto/aluno na educação básica foi $75 \%$ acima do gasto/aluno no ensino médio declarado no siope. Assim, vamos encontrar valores como R\$ 19/aluno-ano no Mato Grosso; R\$ 74, no Acre; R\$373, no Maranhão, e assim por diante. As duas últimas colunas da tabela propiciam uma comparação entre a participação do ensino médio nos gastos declarados pelos estados em manutenção e desenvolvimento do ensino, em confronto com sua respectiva participação na matrícula da educação básica. Na média do país (última linha da tabela), observa-se que, embora o ensino médio responda por $40 \%$ da matrícula da rede estadual na educação básica, as despesas contabilizadas nesta etapa de ensino no siope respondem por apenas $20 \%$ do total declarado como gasto na educação básica. Outra maneira de se observar a discrepância dos gastos por aluno com o ensino médio declarados ao siope é compará-los com o valor por aluno disponibilizado pelo Fundo de Manutenção e Desenvolvimento da Educação Básica e de Valorização dos Profissionais da Educação (FUndeb) para os mesmos estados (coluna 4 da mesma tabela). A coluna 3 (gasto/aluno na educação básica), no nosso entendimento, é a que mais se aproxima dos valores efetivamente destinados ao ensino médio. Entendemos que essa forma de se obter o valor gasto com o ensino médio é o mais próximo do real, tendo em vista que, segundo dados do mesmo Censo Escolar de 2010, 84\% das matrículas dos estados concentram-se na etapa final do ensino fundamental ou no ensino médio; enquanto $16 \%$ correspondem à oferta nos anos iniciais do ensino fundamental e na educação infantil. Além disso, no que se refere à remuneração docente, item de maior impacto nos gastos, não há diferenças no padrão de remuneração da carreira entre os professores que atuam nos anos finais do ensino fundamental e aqueles do ensino médio, particularmente na rede pública, na qual se encontra a maioria dos professores, uma vez que ambos, por lei, devem possuir formação em nível superior. Mesmo considerando que o salário dos professores que atuam no ensino médio tende a ser um pouco mais elevado que o percebido por aqueles que atuam nos anos finais do ensino fundamental - particularmente na rede privada de ensino, uma vez que os docentes mais experientes e qualificados tendem a optar por lecionar no ensino médio -, a maior razão aluno/ turma (34 alunos por turma no ensino médio contra 32 nos anos finais do ensino fundamental) tende a neutralizar o impacto desse efeito no custo/aluno. Portanto, é razoável supor que os valores destinados ao ensino médio por aluno pelos governos estaduais encontram-se bem próximos da média do gasto/aluno na educação básica como um todo, que é a hipótese que assumiremos neste artigo. 
Contudo, como também se pode observar na Tabela 3, embora as discrepâncias entre os gastos/aluno na educação básica e os recursos/aluno disponibilizados pelo FUNDEB sejam menores, elas ainda são significativas para alguns estados. A Tabela 4 procura exatamente aquilatar esta distância entre os gastos/aluno na educação básica e os valores por aluno disponibilizados pelo FUNDEB, trazendo como possíveis elementos de explicação o grau de municipalização do ensino (coluna 3 da Tabela 4), ou a subcontabilização dos gastos com educação superior (coluna 4 da mesma tabela).

\section{Tabela 4}

Razão entre o gasto/aluno na educação básica declarado no sıope e o valor potencialmente disponibilizado pelo FUNDEB para o ensino médio, comparado com a participação da rede estadual na matrícula pública de educação básica e com o gasto/aluno declarado na educação superior -2008

\begin{tabular}{|c|c|c|c|}
\hline & $\begin{array}{c}(2) \\
\text { Razão } \\
\text { Gasto ed. básica/Valor } \\
\text { aluno FUNDEB EM }\end{array}$ & $\begin{array}{c}(3) \\
\text { Participação da rede } \\
\text { estadual na matrícula } \\
\text { pública } \\
\%\end{array}$ & $\begin{array}{c}\text { (4) } \\
\text { Gasto/aluno declarado } \\
\text { na educação superior }\end{array}$ \\
\hline $\mathrm{AC}$ & 1,4 & 64 & - \\
\hline $\mathrm{AL}$ & 1,6 & 29 & 1.716 \\
\hline $\mathrm{AP}$ & 1,4 & 71 & - \\
\hline $\mathrm{AM}$ & 1,1 & 46 & 284 \\
\hline BA & 1,5 & 32 & 808 \\
\hline $\mathrm{CE}$ & 1,7 & 25 & 2.168 \\
\hline DF & 1,9 & 100 & - \\
\hline ES & 1,2 & 37 & 13.085 \\
\hline GO & 1,5 & 49 & 864 \\
\hline MA & 1,4 & 25 & 4.367 \\
\hline MT & 1,2 & 55 & 7.888 \\
\hline MS & 1,3 & 48 & 13.327 \\
\hline MG & 1,6 & 56 & 1.128 \\
\hline $\mathrm{PA}$ & 1,2 & 31 & - \\
\hline $\mathrm{PB}$ & 1,0 & 41 & 8.995 \\
\hline PR & 1,4 & 56 & 8.595 \\
\hline PE & 1,4 & 41 & 3.151 \\
\hline PI & 1,3 & 35 & 27 \\
\hline RJ & 2,0 & 41 & 4.996 \\
\hline RN & 1,4 & 41 & 8.881 \\
\hline
\end{tabular}




\begin{tabular}{|c|c|c|c|}
\hline RS & 1,1 & 55 & - \\
\hline RO & 1,3 & 58 & 1.822 \\
\hline RR & 1,4 & 65 & 21.402 \\
\hline SC & 1,5 & 50 & 28.732 \\
\hline SP & 1,2 & 55 & - \\
\hline SE & 1,4 & 42 & - \\
\hline TO & 1,4 & 57 & \\
\hline
\end{tabular}

Fonte: SIOPE e FNDE.

Embora haja uma variação na razão entre o gasto/aluno na educação básica e o valor/aluno potencialmente disponibilizado pelo FUNDEB, podemos considerar que eles se encontram dentro de uma margem razoável, até porque o este Fundo não engloba o total de recursos destinados à educação. Além disso, nos termos da Lei n. 11.494/2007, que regulamenta o Fundo, não há necessidade de que os valores contabilizados referentes aos alunos do ensino médio sejam efetivamente aplicados nesta etapa de ensino; trata-se, tão somente, de uma referência utilizada no âmbito de cada unidade da Federação para definir a distribuição dos recursos entre estados e municípios (ver, em especial, $\S 1^{\text {o }}$ do art. 21 da referida Lei). Do total de unidades federadas listadas, em $68 \%$ esta diferença é de até $40 \%$. Onde esta diferença é superior a este índice podemos indicar elementos associados a uma forte municipalização da educação básica (Alagoas e Ceará), ou ao subdimensionamento dos gastos na educação superior estadual (Minas Gerais e Goiás), ou aos dois fatores somados (Rio de Janeiro e Piauí, Bahia e Amazonas). O Distrito Federal é um caso à parte: a diferença de duas vezes se explica pelo fato da metade do total de recursos contabilizados como gastos na educação básica advir do governo federal, em função de determinação constitucional. Considerando que a diferença entre os recursos estaduais destinados aO FUNDEB e aqueles constitucionalmente destinados à manutenção e desenvolvimento do ensino é de cerca de $25 \%$, podemos dizer que a nossa estimativa de gasto por aluno do ensino médio como equivalente ao gasto por aluno da educação básica pode ser considerada uma boa aproximação da realidade. Considerando, ainda, que muitos estados contabilizam como gastos com manutenção e desenvolvimento do ensino o pagamento de professores e demais profissionais do magistério aposentados, podemos ressaltar que os valores indicados ainda podem estar superestimados. A título de exemplo, no Rio Grande do Sul - um dos estados que entraram com ação junto ao Superior Tribunal Federal (STF) alegando inconstitucionalidade do Piso Salarial Profissional Nacional de R\$ 950 por mês -, a folha de aposentados é superior aos pagamentos dos profissionais em efetivo exercício. 
Portanto, para efeito de uma análise inicial, tomaremos os gastos por aluno da educação básica obtidos a partir do sıope como uma primeira aproximação dos gastos estaduais com o ensino médio, com os cuidados indicados, em especial para o Rio de Janeiro, Minas Gerais, Piauí, Amazonas e Ceará, nos quais, tudo indica, gastos na educação superior estão sendo contabilizados na educação básica. A tabela a seguir traz, novamente, os dados de 2008 juntamente com aqueles de 2009, em ordem crescente para os valores deste último ano, para que possamos ter um parâmetro de comparação.

\section{Tabela 5}

Gastos/aluno na educação básica nas redes estaduais (2008-2009)

(R\$ de 2009)

\begin{tabular}{|c|c|c|}
\hline & 2.008 & 2009 \\
\hline РВ & 1.441 & 1.838 \\
\hline BA & 2.167 & 1.838 \\
\hline $\mathrm{AM}$ & 2.972 & 1.944 \\
\hline PA & 1.691 & 2.054 \\
\hline MA & 2.033 & 2.106 \\
\hline RN & 2.374 & 2.121 \\
\hline $\mathrm{AL}$ & 2.273 & 2.147 \\
\hline PI & 1.853 & 2.198 \\
\hline RO & 2.554 & 2.476 \\
\hline PR & 2.414 & 2.505 \\
\hline RS & 2.373 & 2.542 \\
\hline MG & 2.878 & 2.597 \\
\hline $\mathrm{PE}$ & 2.068 & 2.631 \\
\hline MT & 2.379 & 2.644 \\
\hline $\mathrm{SC}$ & 3.022 & 2.759 \\
\hline $\mathrm{CE}$ & 2.387 & 2.807 \\
\hline GO & 2.658 & 2.818 \\
\hline то & 3.036 & 3.034 \\
\hline SE & 2.554 & 3.174 \\
\hline $\mathrm{RJ}$ & 3.364 & 3.220 \\
\hline $\mathrm{AC}$ & 3.469 & 3.318 \\
\hline SP & 3.238 & 3.349 \\
\hline MS & 3.047 & 3.533 \\
\hline $\mathrm{AP}$ & 3.751 & 3.742 \\
\hline ES & 3.524 & 3.795 \\
\hline
\end{tabular}




\begin{tabular}{|l|r|r|}
\hline RR & 4.612 & 4.403 \\
\hline DF & 4.492 & 6.206 \\
\hline Brasil & 2.788 & 2.843 \\
\hline Desvio Padrão & $28 \%$ & $33 \%$ \\
\hline
\end{tabular}

Fonte: sIope e Censo Escolar.

Obs: Correção pelo IPCA-IBGE. ${ }^{1}$

A primeira e principal conclusão que podemos tirar dos dados apresentados nesta tabela, mesmo considerando que, possivelmente, alguns deles estejam superestimados, é sobre o baixo valor do gasto/aluno. As escolas privadas frequentadas pelos jovens das famílias de classe média praticam anuidades próximas a $R \$ 10.400$ (considerando R \$ 800/mês x 12 meses + matrícula), sem falar na taxa de material didático. Em comparação ao PIB per capita de 2008 e 2009, esses valores praticados pelas redes estaduais correspondem, respectivamente, a $16,6 \%$ e $17,1 \%$, enquanto na média dos países da oCDE, este índice é de $26 \%$ do PIB per capita, em 2006 (OCDE, 2009), o que representa um gasto/aluno muito maior, não só em termos absolutos, uma vez que a sua riqueza por habitante é maior, mas também em termos de esforço relativo, o que não se justifica. A segunda observação refere-se à persistente diferença nos gastos/aluno entre as unidades da Federação. Embora o desvio padrão não seja muito elevado (28\%, em 2008, e 33\%, em 2009), a diferença entre o maior e o menor valor no gasto/aluno é superior a três vezes, o que mostra os limites ainda existentes da política de fundos, decorrentes, em particular, da pequena participação da União (menos de 10\% do total) nos recursos do FUnDEb. Cabe ainda comentar que, no biênio considerado, em 11 estados houve uma redução no valor declarado do gasto/aluno do ensino médio. Com base nos dados do siope, estimamos os gastos dos estados com o ensino médio em cerca de $0,7 \%$ do Рів/ano, considerando do biênio 2008-2009.

\section{Os gastos federais}

\section{Gasto público do governo federal na educação e no ensino médio}

Nesta seção, serão analisados os gastos realizados pelo governo federal na política educacional para o período de 1995 a 2009. Para estudar a atuação do Estado na área educacional, aplica-se o conceito de Gasto Público Educacional do governo federal, que compreende os recursos financeiros brutos empregados pelo setor público no atendimento das necessidades e direitos educacionais. Os resultados dos gastos efetivos e estimados pelas principais subáreas são apresentados na Tabela 6, com valores corrigidos para 2009 pelo IPCA médio e para a relação com o PIB, além de se apresentar a importância relativa de cada subárea. 


\section{Tabela 6}

Gasto federal com a educação por subáreas (1995-2009)

\begin{tabular}{|c|c|c|c|c|c|c|c|c|c|c|c|c|c|c|c|}
\hline Subáreas & 1995 & 1996 & 1997 & 1998 & 1999 & 2000 & 2001 & 2002 & 2003 & 2004 & 2005 & 2006 & 2007 & 2008 & 2009 \\
\hline & \multicolumn{15}{|c|}{ Gasto corrigido pelo IPCA para 2009 (em R\$ bilhões) } \\
\hline $\begin{array}{l}\text { Assistência a } \\
\text { Educandos }\end{array}$ & 2,3 & 1,6 & 1,8 & 2,1 & 2,3 & 3,5 & 2,5 & 2,4 & 2,3 & 2,6 & 3,0 & 3,2 & 3,3 & 3,9 & 4,4 \\
\hline $\begin{array}{l}\text { Educação da } \\
\text { Criança de } 0 \text { a } 6 \\
\text { Anos }\end{array}$ & 0,0 & 0,0 & 0,0 & 0,0 & - & 0,0 & 0,0 & 0,1 & 0,0 & 0,0 & 0,0 & 0,0 & 0,3 & 0,5 & 0,8 \\
\hline $\begin{array}{l}\text { Ensino } \\
\text { Fundamental }\end{array}$ & 3,1 & 2,9 & 2,0 & 3,3 & 2,8 & 3,0 & 2,8 & 2,0 & 2,6 & 2,2 & 2,0 & 2,9 & 4,9 & 4,4 & 6,0 \\
\hline $\begin{array}{l}\text { Ensino Médio e } \\
\text { Profissionalizante }\end{array}$ & 1,3 & 1,0 & 1,0 & 1,0 & 1,1 & 1,4 & 2,0 & 1,9 & 1,1 & 1,6 & 1,5 & 1,5 & 2,0 & 2,7 & 3,7 \\
\hline Ensino Superior & 12,0 & 10,4 & 10,3 & 9,3 & 9,7 & 10,3 & 10,1 & 10,1 & 9,4 & 10,2 & 11,2 & 12,2 & 13,8 & 14,2 & 17,1 \\
\hline $\begin{array}{l}\text { Ensino Supletivo } \\
\text { e Educação de } \\
\text { Jovens e Adultos }\end{array}$ & 0,0 & 0,1 & 0,1 & 0,1 & 0,1 & 0,1 & 0,5 & 0,7 & 0,7 & 0,8 & 1,0 & 0,8 & 0,4 & 1,1 & 1,5 \\
\hline Outros & 1,9 & 1,8 & 1,7 & 2,6 & 2,3 & 2,3 & 2,3 & 2,2 & 2,1 & 2,6 & 3,2 & 3,7 & 3,4 & 3,4 & 3,6 \\
\hline \multirow[t]{2}{*}{ Total } & 20,7 & 17,7 & 16,9 & 18,4 & 18,2 & 20,7 & 20,2 & 19,3 & 18,2 & 20,0 & 21,8 & 24,3 & 28,1 & 30,2 & 37,1 \\
\hline & \multicolumn{15}{|c|}{ Relação gasto/Pıв (em \%) } \\
\hline $\begin{array}{l}\text { Assistência a } \\
\text { Educandos }\end{array}$ & 0,13 & 0,08 & 0,09 & 0,11 & 0,11 & 0,16 & 0,11 & 0,10 & 0,10 & 0,10 & 0,12 & 0,12 & 0,11 & 0,12 & 0,14 \\
\hline $\begin{array}{l}\text { Educação da } \\
\text { Criança de } 0 \text { a } 6 \\
\text { Anos }\end{array}$ & 0,00 & 0,00 & 0,00 & 0,00 & - & 0,00 & 0,00 & 0,00 & 0,00 & 0,00 & 0,00 & 0,00 & 0,01 & 0,02 & 0,03 \\
\hline $\begin{array}{l}\text { Ensino } \\
\text { Fundamental }\end{array}$ & 0,17 & 0,15 & 0,10 & 0,16 & 0,14 & 0,14 & 0,13 & 0,09 & 0,11 & 0,09 & 0,08 & 0,11 & 0,17 & 0,14 & 0,19 \\
\hline $\begin{array}{l}\text { Ensino Médio e } \\
\text { Profissionalizante }\end{array}$ & 0,07 & 0,05 & 0,05 & 0,05 & 0,05 & 0,07 & 0,09 & 0,08 & 0,05 & 0,06 & 0,06 & 0,05 & 0,07 & 0,09 & 0,12 \\
\hline Ensino Superior & 0,66 & 0,55 & 0,52 & 0,47 & 0,47 & 0,48 & 0,46 & 0,44 & 0,41 & 0,41 & 0,43 & 0,45 & 0,47 & 0,45 & 0,54 \\
\hline $\begin{array}{l}\text { Ensino Supletivo } \\
\text { e Educação de } \\
\text { Jovens e Adultos }\end{array}$ & 0,00 & 0,00 & 0,00 & 0,00 & 0,00 & 0,00 & 0,02 & 0,03 & 0,03 & 0,03 & 0,04 & 0,03 & 0,01 & 0,04 & 0,05 \\
\hline Outros & 0,11 & 0,09 & 0,09 & 0,13 & 0,11 & 0,11 & 0,10 & 0,09 & 0,09 & 0,11 & 0,12 & 0,14 & 0,11 & 0,11 & 0,11 \\
\hline Total & 1,13 & 0,93 & 0,86 & 0,92 & 0,88 & 0,97 & 0,92 & 0,84 & 0,79 & 0,81 & 0,85 & 0,89 & 0,95 & 0,96 & 1,18 \\
\hline
\end{tabular}




\begin{tabular}{|c|c|c|c|c|c|c|c|c|c|c|c|c|c|c|c|}
\hline & \multicolumn{15}{|c|}{ Participação percentual (em \%) } \\
\hline $\begin{array}{l}\text { Assistência a } \\
\text { Educandos }\end{array}$ & 11,2 & 8,9 & 10,5 & 11,6 & 12,6 & 16,8 & 12,2 & 12,2 & 12,8 & 13,0 & 13,6 & 13,2 & 11,8 & 13,0 & 11,8 \\
\hline $\begin{array}{l}\text { Educação da } \\
\text { Criança de } 0 \text { a } 6 \\
\text { Anos }\end{array}$ & 0,1 & 0,2 & 0,3 & 0,2 & - & 0,2 & 0,2 & 0,3 & 0,1 & 0,1 & 0,1 & 0,1 & 1,1 & 1,7 & 2,1 \\
\hline $\begin{array}{l}\text { Ensino } \\
\text { Fundamental }\end{array}$ & 14,7 & 16,1 & 11,9 & 17,7 & 15,4 & 14,6 & 14,0 & 10,5 & 14,5 & 11,0 & 9,4 & & 17,5 & 14,6 & 16,3 \\
\hline $\begin{array}{l}\text { Ensino Médio e } \\
\text { Profissionalizante }\end{array}$ & 6,2 & 5,6 & 5,8 & 5,2 & 5,9 & 7,0 & 9,8 & 9,6 & 5,9 & 8,0 & 6,8 & 6,0 & 7,1 & 9,0 & 10,1 \\
\hline Ensino Superior & 58,1 & 58,9 & 60,9 & 50,6 & 53,2 & 49,8 & 50,1 & 52,5 & 51,8 & 51,0 & 51,1 & 50,0 & 49,1 & 46,9 & 46,1 \\
\hline $\begin{array}{l}\text { Ensino Supletivo } \\
\text { e Educação de } \\
\text { Jovens e Adultos }\end{array}$ & 0,1 & 0,3 & 0,4 & 0,4 & 0,3 & 0,3 & 2,4 & 3,6 & 3,7 & 3,8 & 4,5 & 3,5 & 1,4 & 3,8 & 4,0 \\
\hline Outros & 9,4 & 9,9 & 10,2 & 14,3 & 12,6 & 11,3 & 11,3 & 11,3 & 11,3 & 13,2 & 14,6 & 15,3 & 12,0 & 11,1 & 9,6 \\
\hline Total & 100,0 & 100,0 & 100,0 & 100,0 & 100,0 & 100,0 & 100,0 & 100,0 & 100,0 & 100,0 & 100,0 & 100,0 & 100,0 & 100,0 & 100,0 \\
\hline
\end{tabular}

Fonte: IPEA/DISOC. Elaborada pelos autores.

Os dados desta tabela mostram que, em termos absolutos, os gastos foram bastante irregulares em quase todos os níveis/modalidades, com crescimento mais forte no final do período, com o ensino médio ampliando seus gastos mais rapidamente do que os demais. Quando os dados são analisados de forma relativa, a trajetória dos gastos é também irregular, nem sempre crescente ou estável. Para melhor visualização, são apresentados no Gráfico 1 os resultados dos gastos realizados na área educacional e no ensino médio pelo governo federal, com valores corrigidos para 2009 pelo IPCA médio.

Os dados revelam uma ampliação real do gasto total em educação realizado pelo governo federal no período transcorrido entre 1995 e 2009, saindo de R\$20,7 bilhões para R \$37,1 bilhões, um crescimento real de 79\% em 14 anos, equivalente a 5,6\% ao ano (v. Gráfico 1 [a]). Esse crescimento, contudo, não ocorreu de forma constante; houve anos em que os aumentos giraram em torno de $15,1 \%$, outros em que atingiram apenas $1 \%$. Por outro lado, também se observam dois momentos de queda dos recursos: entre 1996 e 1999, quando estes caem 12\%, comparando 1999 com 1995; e entre 2001 e 2004, quando caem 3\%, comparando 2004 com 2000. Daí em diante, os recursos crescem constantemente, quase dobrando, quando comparamos 2009 com 2004.

Já os dados do ensino médio têm praticamente o mesmo movimento observado para o gasto em educação como um todo, saindo de $\mathrm{R} \$ 1,3$ para $\mathrm{R} \$ 3,7$ bilhões, um 
crescimento de $189 \%$, índice bem superior àquele verificado para educação como um todo (v. Gráfico $1[\mathrm{~b}]$ ). O diferencial é o ritmo de crescimento, que oscilou mais, com uma grande expansão a partir de 2006, de tal forma que, entre 2006 e 2009, o crescimento foi de $147 \%$, uma média de quase $50 \%$ ao ano! Portanto, essa subárea foi uma daquelas que ajudou a puxar os gastos federais no período. Há que se comentar, contudo, que seu ponto de partida foi muito baixo.

\section{Gráfico 1}

Gasto federal em educação e no ensino médio (1995-2009)

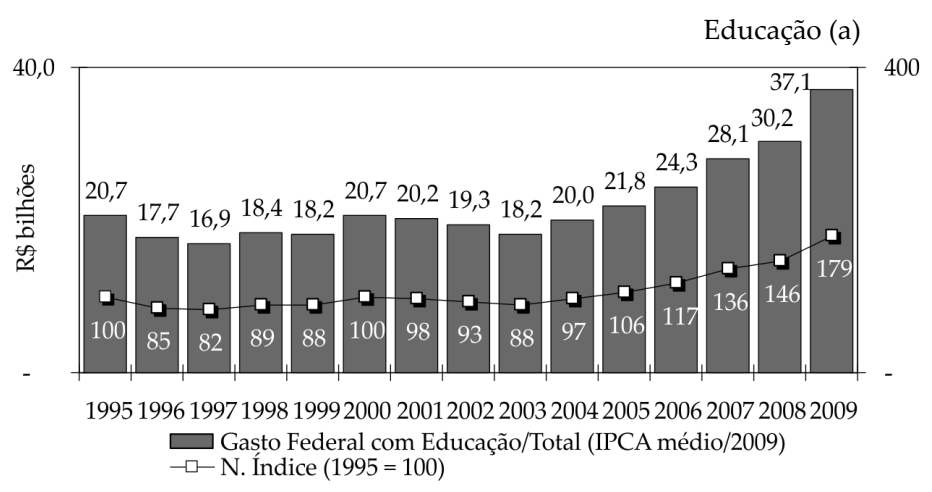

Ensino Médio (b)

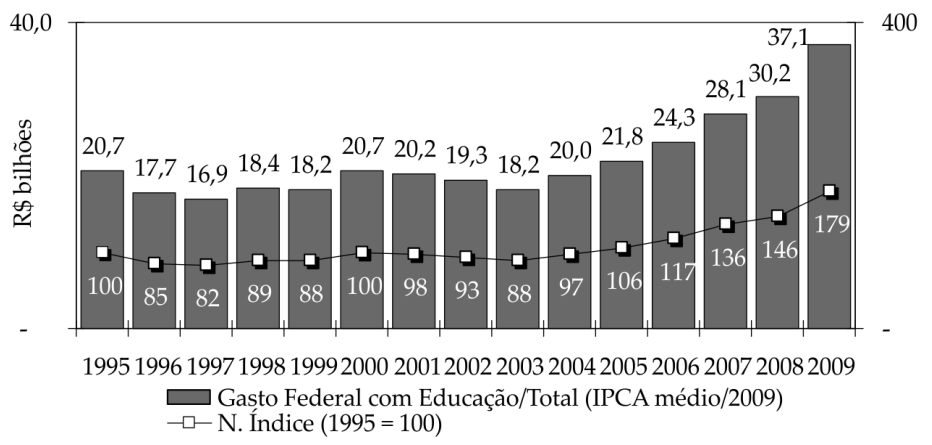

Fonte: DISOc/IPEA. Elaborado pelos autores.

Por isso mesmo, observa-se no Gráfico 2 que a importância relativa do ensino médio nos gastos educacionais amplia-se no período. Saindo de $6,2 \%$ de peso relativo nos gastos para cerca de 10\%, nos anos de 2001 e 2002, caindo em seguida e retomando um patamar constante de crescimento em 2006, até ultrapassar levemente o nível de 2001 somente em 2009. Esses dados podem indicar um maior comprometimento da esfera federal com o ensino médio, rompendo o padrão até então 
vigente, de grande dominância de gastos com o ensino superior. De qualquer forma, é preciso observar a tendência dos próximos anos.

\section{Gráfico 2}

Percentual de gasto no ensino médio do governo federal em relação ao gasto total (1995-2009)

15,0

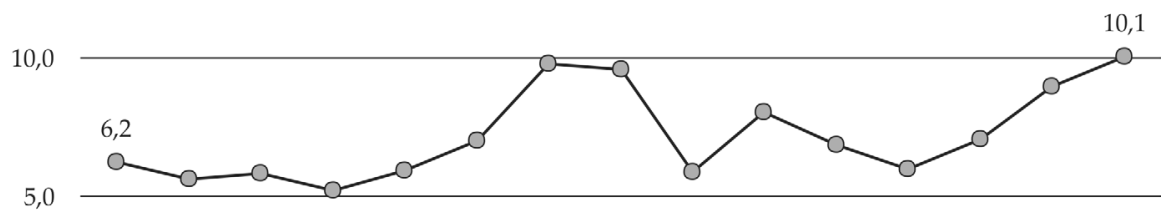

$\begin{array}{lllllllllllllll}1995 & 1996 & 1997 & 1998 & 1999 & 2000 & 2001 & 2002 & 2003 & 2004 & 2005 & 2006 & 2007 & 2008 & 2009\end{array}$

- - Ensino Médio

Fonte: DISOC/IPEA.

Este mesmo movimento pode ser observado quando se utiliza outro indicador do financiamento da educação: a proporção do PIв que é investida em educação. Conforme mostra o gráfico a seguir, os gastos do governo federal oscilaram sempre abaixo de $1 \%$ do рів no período 1996 a 2008, chegando mesmo a representar cerca de 0,73\% do РIв, em 2003. A partir desta data, recupera importância até superar a marca de 1995, quando chega a 1,1\% do РIв, em 2009. Isto significou um crescimento de apenas 4\%, em termos de PIB, entre 1995 e 2009.

Este mesmo movimento é verificado para o caso dos gastos com ensino médio, apenas com um detalhe: nesta situação, a recuperação do poder de gasto ocorre de forma mais vigorosa que aquela verificada para os gastos totais. Conforme mostra o Gráfico 3, os gastos do governo federal no ensino médio sempre estiveram próximos a 0,07\% do PIB no período 1995 a 2007, ficando em grande parte do período em 0,05\% do Рів. A partir de 2007 recupera importância até chegar 0,12\% em 2009. Isto significou um crescimento de 71\%, em termos de percentual do PIB, entre 1995 e 2009. Como estimamos (média 2008-2009) os gastos estaduais com o ensino médio em cerca de $0,7 \%$ do PIB, os gastos federais, para o mesmo período, representariam cerca de $15 \%$ do valor gasto pelos estados.

Historicamente, os recursos federais na rubrica do ensino médio eram destinados basicamente à rede federal de escolas técnicas e aos colégios de aplicação 
vinculados às instituições federais de ensino superior (IFEs). Com o FUNDEB e com a ampliação das transferências voluntárias, os estados também estão recebendo recursos federais para esta etapa da educação básica, o que pode explicar o crescimento a partir de 2007, indicado no Gráfico 3. A ampliação da rede federal de educação profissional técnica também ajuda a entender este crescimento. Esta última será analisada no próximo item.

\section{Gráfico 3}

Percentual de gasto no ensino médio do governo federal, em relação ao PIB (1995-2009)

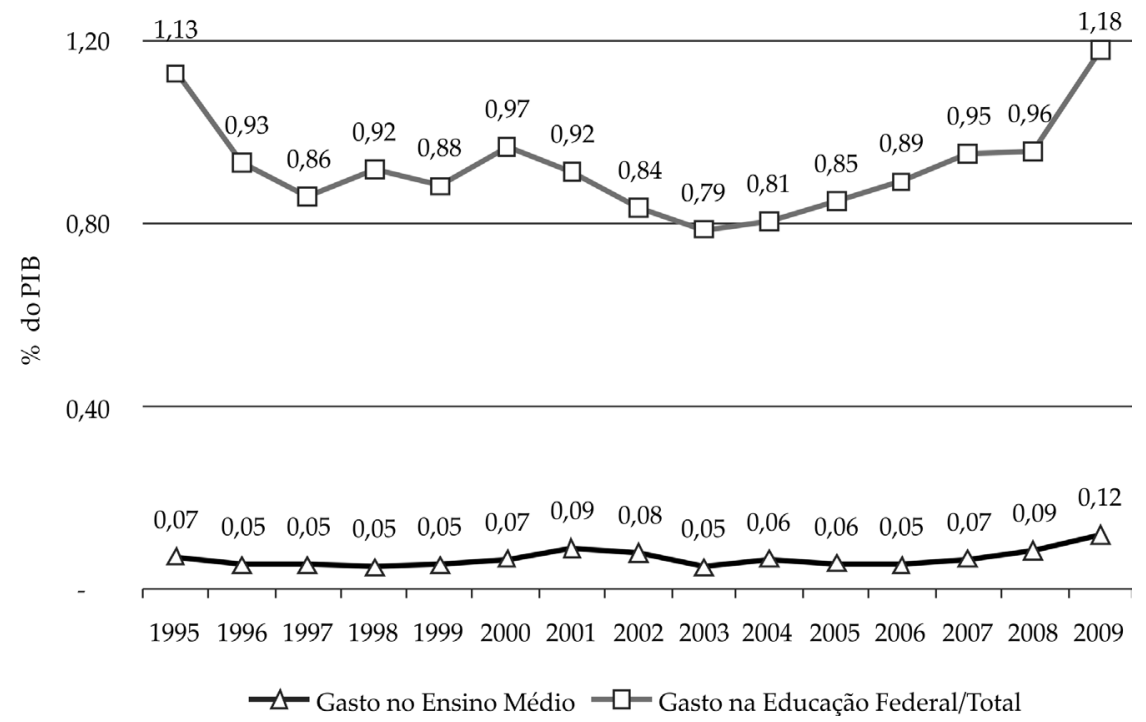

Fonte: SIAFI/SIDOR.

\section{A rede de educação federal e seus custos}

O estudo do ensino médio (Ем) e da educação profissional técnica de nível médio na rede federal se torna ainda mais complexo que a análise dos gastos estaduais, pois essas etapas e modalidades são oferecidas em instituições que, além de ofertarem outras etapas da educação básica (вв), também ofertam a educação superior.

Na esfera federal, o ensino médio e a educação profissional técnica de nível médio, anteriormente à Lei n. 11.892/2008 - que instituiu a Rede Federal de Educação Profissional, Científica e Tecnológica e criou os Institutos Federais de Educação, Ciência e Tecnologia - eram oferecidos pelo Colégio Pedro II, nas Escolas Técnicas Federais (ETF), nas Escolas Agrotécnicas Federais (EAF), nos Centros Federais de 
Educação Tecnológica (CEFET) e nos Colégios de Aplicação (CAP) vinculados às IFEs. Com a reformulação implementada pela Lei n. 11.892, a rede federal que oferece o ensino médio e a educação tecnológica passou a se constituir do Colégio Pedro II, dos Institutos Federais de Educação, Ciência e Tecnologia (IF), da Universidade Tecnológica Federal do Paraná (Utfrp), dos cefet do Rio de Janeiro e de Minas Gerais e das Escolas Técnicas e CAP vinculados às IFEs. Neste estudo separaremos a rede federal em IFes e não IFEs, incluindo nestas últimas, portanto, o Colégio Pedro II, os If, a UtFPr e os Cefet do Rio de Janeiro e de Minas Gerais.

O estudo dos alunos da вв da rede federal apresenta outra dificuldade que é a inexistência no Censo Escolar de uma separação entre estudantes das IFEs e não IFEs. Dessa forma, utilizaremos informações da Associação Nacional dos Dirigentes das Instituições Federais de Ensino Superior (ANDIFEs) para o ano de 2000 e informações contidas nos Relatórios Anuais que as IFes apresentam ao Tribunal de Contas da União (TCU), por serem Unidades Orçamentárias (Uo) no orçamento da União.

Os estudantes da вв matriculados nas Escolas Técnicas e Colégios de Aplicação vinculados às IFEs eram, em 2000, 43.458 (ANDIFEs, 2002) e como o Censo Escolar de 2000 apurou que as matrículas federais na вв eram de 154.645 alunos, concluímos que nas instituições não IFEs estavam matriculados 111.187 estudantes.

No ano de 2008, os relatórios anuais das instituições apresentaram um total de 67.367 estudantes nas Ifes (Brasil; Tcu, 2011). Destes, apenas 5.223 estavam na educação infantil e no ensino fundamental e como eram 197.532 estudantes pelo Censo de 2008, concluímos que nas não ifEs estavam matriculados 130.165 estudantes, sendo 24.204 na educação infantil ou no ensino fundamental. Diante da impossibilidade de separar, na execução orçamentária das instituições de ensino federais, os valores aplicados nas etapas e modalidades da educação básica, entendemos que não haverá grandes alterações nos valores aplicados por aluno no EM, considerando o pequeno quantitativo de crianças na educação infantil e no ensino fundamental. A tabela a seguir sintetiza os grandes números relacionados às matrículas das IFES e não IFEs.

Tabela 7

Matrículas nas instituições de ensino federais (2000 e 2008)

\begin{tabular}{|l|c|c|}
\hline Instituições & 2000 & 2008 \\
\hline IFES & 43.458 & 67.367 \\
\hline não IFES & 111.187 & 130.165 \\
\hline Total & $\mathbf{1 5 4 . 6 4 5}$ & $\mathbf{1 9 7 . 5 3 2}$ \\
\hline
\end{tabular}

Fonte: Censo da Educação Superior. 
Deve-se registrar ainda que as não IFEs, em 2000, apresentavam apenas 3.134 estudantes matriculados na educação superior (ES). Já em 2008 esse perfil estava profundamente alterado, passando para 37.967 estudantes, segundo informações apuradas do Censo da Educação Superior de 2000 e de 2008. Se em 2008 elas possuíam 130.165 estudantes de EB, esse contingente de alunos da Es já significa o equivalente a $29,2 \%$ dos alunos da Ев.

As não IFEs, considerando todas as fontes, todas as despesas de pessoal, outros custeios e capital, apurados da execução orçamentária do governo federal (disponível em: www.camara.gov.br), gastaram um total de R\$1,4 bilhões, em 2000, e R \$ 2,24 bilhões, em 2008, a preços de 2009, corrigidos pelo IPCA. No total de recursos de 2000 estavam incluídos os 3.134 estudantes de Es e, no total de recursos de 2008, os 37.967 alunos de Es.

Em 2000, se considerarmos que o quantitativo de alunos na es é muito pequeno em relação ao quantitativo de alunos da EB, é razoável considerar que o valor aplicado por aluno da вв pode ser obtido pela divisão do total executado pelas não IFEs e o total de matrículas na educação básica (111.187), o que resulta em $\mathrm{R} \$ 12.591$, a preços de 2009, corrigidos pelo IPCA.

Em 2008, há que se retirar dos recursos executados pelas não IFEs o equivalente a 37.967 estudantes de Es que se encontravam matriculados. Para isso, adotaremos a seguinte sistemática: o valor por aluno das não IFEs, sem considerar a retirada de recursos dedicados à $\mathrm{Es}$, é de $\mathrm{R} \$ 17.210$ (obtido dividindo-se $\mathrm{R}$ \$2,24 bilhões por 130.165) e o valor por estudante da educação superior nas IFEs, que foi de $\mathrm{R} \$ 28.638$, considerando-se todas as despesas e todas as fontes da execução orçamentária dessas instituições. Consideraremos, então, que o valor por aluno matriculado na educação superior das não IFEs seria a média desses dois, ou seja, $\mathrm{R} \$ 22.924$, pois estas instituições desenvolvem atividades de pesquisa e extensão em menor intensidade que as IFEs.

Dessa forma, devemos retirar do montante das não IFes executado em 2008 um total de $\mathrm{R} \$ 870$ milhões, que é o resultado do produto de 37.967 estudantes por $\mathrm{R} \$ 22.924$.

Concluímos, assim, que, em 2008, foram aplicados $\mathrm{R} \$ 1,37$ bilhões para um total de 130.165 da Eв, o que resulta em um valor por aluno de $\mathrm{R} \$ 10.525$, a preços de 2009.

Portanto, em 2000 o valor aplicado por aluno na Ев nas instituições federais foi de $R \$ 12.591$, caindo para $R$ \$ 10.525 , em 2008, o que indica uma queda de $16 \%$ em termos reais. Estudos realizados por Amaral (2011), ao analisar a evolução dos custos médios da educação superior nas IFEs, mostram que não houve queda nesses 
custos, quando se compara o ano de 2000 com o ano de 2008, mas sim uma elevação de 5,9\%, o que explicita mais ainda a queda no valor aplicado por aluno da EB.

Constata-se, portanto, também na esfera federal que a expansão de matrículas na ев ocorreu pela via do rebaixamento do valor gasto por aluno, contribuindo também para o processo de massificação barata da rede pública, apesar de ainda continuar aplicando valores substancialmente maiores que as redes públicas estaduais. Nunca é demais ressaltar que, mesmo com a queda observada no valor/aluno na rede federal, o valor/aluno estimado para 2008 desta rede é cerca de quatro vezes o gasto na rede estadual e é um montante próximo àquele cobrado pelas escolas da rede privada frequentadas pela classe média alta. A diferença é que as escolas federais, não obstante também atender a segmentos de classe média, recebem alunos com um perfil socioeconômico menos elitizado que as escolas privadas, asseguram profissionalização com qualidade e conseguem um bom desempenho nos processos seletivos das boas universidades.

\section{Os recursos públicos administrados pelo setor privado: o Sistema S}

No país, desde 1942, com a criação do Serviço Nacional de Aprendizagem Industrial (SENAI) foi estabelecido um amplo sistema que envolve atividades de formação profissional e de assistência social aos trabalhadores, conhecido como "Sistema $S^{\prime \prime}$. A principal característica deste sistema é que, muito embora ele seja financiado por tributos que incidem basicamente sobre a folha de salários das empresas e que são recolhidos pela Receita Federal, a posse e gestão destes recursos ficam nas mãos das entidades de caráter patronal. Trata-se, portanto, de tributos que, em última análise, são pagos pelo conjunto da população, uma vez que seu valor é repassado ao preço final dos produtos, mas sobre os quais a sociedade não possui quase nenhum controle, uma vez que não entram no orçamento público. O quadro a seguir apresenta informações básicas sobre este sistema.

\section{Quadro 1}

Composição do "Sistema S"

\begin{tabular}{|l|l|l|}
\hline Identificação/ano de criação & Finalidade & Recursos \\
\hline $\begin{array}{l}\text { SENAI - Serviço Nacional de } \\
\text { Aprendizagem Industrial } \\
(1942)\end{array}$ & $\begin{array}{l}\text { Organização de escolas de } \\
\text { aprendizagem industrial. }\end{array}$ & $\begin{array}{l}1,0 \% \text { incidente sobre o total } \\
\text { da remuneração paga pelas } \\
\text { empresas do setor industrial. }\end{array}$ \\
\hline
\end{tabular}




\begin{tabular}{|c|c|c|}
\hline $\begin{array}{l}\text { SESI - Serviço Social da } \\
\text { Indústria (1946) }\end{array}$ & $\begin{array}{l}\text { Organização de atividades } \\
\text { que contribuam para o bem } \\
\text { estar social dos trabalhadores } \\
\text { na indústria. }\end{array}$ & $\begin{array}{l}1,5 \% \text { incidente sobre o total } \\
\text { da remuneração paga pelas } \\
\text { empresas do setor industrial. }\end{array}$ \\
\hline $\begin{array}{l}\text { SENAC - Serviço Nacional de } \\
\text { Aprendizagem do Comércio } \\
(1946)\end{array}$ & $\begin{array}{l}\text { Organização de escolas de } \\
\text { aprendizagem comercial. }\end{array}$ & $\begin{array}{l}1,0 \% \text { incidente sobre o total } \\
\text { da remuneração paga pelas } \\
\text { empresas comerciais. }\end{array}$ \\
\hline $\begin{array}{l}\text { SESC - Serviço Social do } \\
\text { Comércio (1946) }\end{array}$ & $\begin{array}{l}\text { Programas que contribuam } \\
\text { para o bem estar social dos } \\
\text { empregados do comércio. }\end{array}$ & $\begin{array}{l}2,0 \% \text { incidentes sobre o total } \\
\text { da remuneração paga pelas } \\
\text { empresas comerciais. }\end{array}$ \\
\hline $\begin{array}{l}\text { SEBRAE - Serviço Brasileiro de } \\
\text { Apoio às Pequenas e Médias } \\
\text { Empresas (1990) }\end{array}$ & $\begin{array}{l}\text { Programas de apoio ao } \\
\text { desenvolvimento das } \\
\text { pequenas e micro empresas. }\end{array}$ & $\begin{array}{l}\text { Alíquota básica: } 0,3 \% \text { sobre o } \\
\text { total das remunerações pagas } \\
\text { pelas empresas contribuintes } \\
\text { do SESI/SENAI e SESC/SENAC } \\
\text { aos seus empregados. }\end{array}$ \\
\hline $\begin{array}{l}\text { SENAR - Serviço Nacional de } \\
\text { Aprendizagem Rural (1991) }\end{array}$ & $\begin{array}{l}\text { Organização de ensino, da } \\
\text { formação profissional rural } \\
\text { e a promoção social do } \\
\text { trabalhador rural. }\end{array}$ & $\begin{array}{l}\text { Alíquota básica: } 2,5 \% \\
\text { incidentes sobre o total de } \\
\text { remuneração paga a todos os } \\
\text { empregados do setor. }\end{array}$ \\
\hline $\begin{array}{l}\text { SEST - Serviço Social de } \\
\text { Transporte (1993) }\end{array}$ & $\begin{array}{l}\text { Programas voltados } \\
\text { à promoção social } \\
\text { do trabalhador em } \\
\text { transporte rodoviário e do } \\
\text { transportador autônomo. }\end{array}$ & $\begin{array}{l}1,5 \% \text { calculado sobre o } \\
\text { montante da remuneração } \\
\text { paga aos empregados, ou } \\
1,5 \% \text { calculado sobre o } \\
\text { salário de contribuição dos } \\
\text { transportadores rodoviários } \\
\text { autônomos. }\end{array}$ \\
\hline $\begin{array}{l}\text { SENAT - Serviço Nacional de } \\
\text { Aprendizagem do Transporte } \\
\text { (1993) }\end{array}$ & $\begin{array}{l}\text { Formação profissional } \\
\text { do trabalhador em } \\
\text { transporte rodoviário e do } \\
\text { transportador autônomo }\end{array}$ & $\begin{array}{l}1,0 \% \text { calculado sobre a } \\
\text { mesma base do SEST. }\end{array}$ \\
\hline
\end{tabular}

Fonte: elaborado a partir de dados disponíveis em: $<\mathrm{http}: / / \mathrm{www}$. receita.fazenda.gov.br/Historico/Arrecadacao/ Carga_Fiscal/1999/SistemaS.htm>

Se houve grandes dificuldades em obter os gastos públicos que impactam no ensino médio, no caso do Sistema $S$ a situação é muito pior. A título de exemplo, vale citar a afirmação do economista Claudio Haddad, diretor-presidente do Instituto 
Brasileiro de Mercado de Capitais (IBMEC, São Paulo), instituição claramente afinada com os interesses do setor empresarial, em evento promovido, em 2008, pelo jornal Folha de S. Paulo:

\begin{abstract}
Tais recursos são compulsórios, o mínimo que se deveria esperar é uma total transparência e total prestação de contas de para onde eles estão indo e, infelizmente, isso não é feito (...). O setor privado dá um mau exemplo porque entrando nos sites do Sistema $\mathrm{S}$, não há uma única cifra, não tem balanços, documentos auditados, nada é divulgado. (Barbieri, 2008)
\end{abstract}

Segundo dados da Receita Federal, a arrecadação do Sistema S, em 2009, atingiu $0,27 \%$ do рів. Considerando a estimativa apresentada no mesmo debate (Barbieri, 2008) de que $40 \%$ dos recursos do sistema são destinados à formação profissional, ter-se-ia o equivalente a $0,11 \%$ do PIB, uma cifra que é praticamente igual ao gasto em ensino médio do governo federal, uma rede de excelente qualidade. Quanto ao atendimento do Sistema S, há pouco o que se dizer, uma vez que o mesmo funciona de forma descentralizada (o sistema é coordenado pelas confederações nacionais - Indústria, Comércio, Agricultura -, as quais, em geral, deixam a cargo de cada federação patronal dos estados o atendimento) e não é sequer contabilizado pelo Censo Escolar. O que se sabe é que, em geral, são cursos de curta duração (cerca de 80 horas) e que cada vez mais são cobrados, embora o sistema, como um todo, gerencie hoje mais de $\mathrm{R} \$ 10$ bilhões de recursos públicos. Se metade destes recursos fosse destinada à formação profissional integrada ao ensino médio, eles permitiriam atender a cerca de $800 \mathrm{mil}$ alunos, considerando um custo/aluno de R \$ 8.000/ano. No segundo mandato do governo Lula, houve um acordo com o Sistema S, mais especificamente SENAI e SESI, pelo qual estas entidades se comprometiam a oferecer vagas gratuitas em percentuais progressivamente maiores até atingir $66 \%$ das matriculas em 2014. Para se verificar se o acordo está sendo efetivamente cumprido, é fundamental que as matrículas do sistema passem a integrar o Censo Escolar, inclusive com indicação do total de matrículas pagas e gratuitas, e das diferentes modalidades de oferta, com a respectiva duração.

Finalmente, cabe comentar que parte dos recursos de formação profissional, arrecadados de forma análoga ao Sistema $S$, são administrados por órgãos públicos. São os casos do Instituto Nacional de Colonização e Reforma Agrária (INCRA), cuja destinação dos recursos deve-se dar na prestação de serviços sociais, no meio rural e em programas de aprendizado das técnicas no campo; da Diretoria de Portos e Costas (DPC), do Ministério da Marinha, e do Fundo Aeroviário (vinculado ao Ministério da Aeronáutica), cujos recursos destinam-se, respectivamente, ao ensino profissional marítimo e aeronáutico. Como se vê, em áreas sensíveis ao setor militar, o Estado não abriu mão de gerir os recursos. Cabe dizer que, de modo análogo ao que ocorre com as entidades empresariais, não há também qualquer informação 
sistemática sobre os atendimentos feitos. Fica a questão: por que não incluir todos estes recursos no FUNDEB, viabilizando um ensino de qualidade que integre a formação escolar com a formação para o trabalho e para a cidadania?

\section{Considerações finais: os recursos financeiros necessários para um ensino médio integrado de qualidade no âmbito de um novo Plano Nacional de Educação}

Ao longo deste trabalho, procuramos mostrar a forte inflexão que o financiamento do ensino médio sofreu no país. De um setor historicamente controlado pela rede privada, e no qual a rede pública, embora de qualidade, ao menos no que se refere às condições de oferta, atendia apenas uma pequena parcela da população, nos últimos quarenta anos assistiu-se a uma expansão significativa e, hoje, $88 \%$ das matrículas encontram-se no setor público. Esse processo, contudo, imprimiu suas marcas nas condições de oferta dessa etapa de ensino. Em 2010, ${ }^{2}$ apenas 15\% das escolas de ensino médio no Brasil organizavam-se para atender apenas essa etapa de ensino; as demais apresentavam diferentes formas de organização, sendo que em mais da metade o ensino médio era oferecido concomitantemente com o ensino fundamental (MEC, 2010). Segundo a mesma fonte, a razão alunos por turma em escolas urbanas, em 2010, era de 30 na rede privada, 31 na rede federal e 34 na rede estadual. Além disso, $82 \%$ dos alunos matriculados na rede estadual estudavam em escolas com jornada de até 5 horas/dia e menos de 1\% estudava em escolas com jornada superior a 6 horas/dia. Com relação a alguns insumos básicos para se garantir qualidade, os dados preocupam: apenas $67 \%$ dos alunos matriculados na rede estadual estudavam em escolas com biblioteca, embora saibamos que a indicação da existência deste equipamento no Censo Escolar não signifique o seu efetivo funcionamento, ou a existência de um profissional habilitado para organizar o seu acervo. Com relação aos laboratórios de ciências, este índice era de apenas 43\%; para quadra de esportes, 72\%; para laboratório de informática e acesso à internet, a participação é superior a $90 \%$. Este último indicador é positivo, mas o que a observação cotidiana das escolas mostra é que o uso da internet é apenas administrativo e os laboratórios de informática ficam geralmente fechados, com acesso restrito aos alunos, além da ausência crônica de manutenção.

Quanto à remuneração dos docentes, dados da PNAD de 2009 mostram que os professores do ensino médio recebem, em média, a metade da remuneração de advogados e economistas, $40 \%$ do rendimento de engenheiros e fiscais de tributação. Seus rendimentos os colocam próximos aos corretores de seguro, cabos e soldados da polícia militar e caixas de banco, que são ocupações que não necessitam de formação em nível superior (Alves \& Pinto, 2011). 
Todos estes dados apontam para a necessidade de um salto de qualidade nas condições de oferta do ensino médio no Brasil. O momento é propício, dada a discussão no Congresso Nacional do Plano Nacional de Educação para o período de 20112020 (PNE, 2011-2020). O Projeto do Executivo, embora aponte para um gasto público em educação de 7\% do PIB em 2020, o que é um avanço frente à situação atual, está distante das diretrizes apontadas pela Conferência Nacional de Educação (CONAE), que determinavam o gasto de $10 \%$ do PIB já em 2014. Acoplados aos desafios da melhoria da qualidade, existem aqueles relacionados à quantidade. Dados da PNAD de 2009 indicam que mais de 27 milhões de brasileiros com 15 anos ou mais de idade não possuem quatro anos de estudo, sendo, portanto, analfabetos funcionais. Na faixa de 18 a 24 anos, 9,5 milhões têm menos de 11 anos de estudo (o equivalente ao ensino médio). Além disso, na faixa etária de 15 a 17 anos, 1,6 milhões estão fora da escola.

Tomando como diretriz básica para um ensino médio de qualidade a integração da formação profissional com a educação básica, podemos fazer uma simulação de demanda de recursos, a partir da definição de um custo/aluno para o ensino médio integrado à formação profissional de $30 \%$ do PIв per capita (cerca de $\mathrm{R} \$ 5.700$ / aluno-ano em valores de 2010, montante que é o dobro do praticado pela rede estadual de ensino médio) e de $40 \%$ do PIB per capita para a educação profissional de nível técnico integrado à formação geral (cerca de $R$ \$ 7.600/aluno-ano em valores de 2010 , o que representa $67 \%$ dos valores praticados pela rede federal). Consideraremos, ainda, como iguais os custos na modalidade chamada regular e aquela de Educação de Jovens e Adultos (EJA), pois não há razão para custos diferenciados, a não ser pela histórica desvalorização da EJA. Do ponto de vista do atendimento, imaginamos para a próxima década o seguinte cenário: 1) uma cobertura no ensino médio na modalidade regular equivalente a $110 \%$ da população de 15 a 17 anos (em função do fluxo escolar), o que representaria uma matrícula de 11,2 milhões de alunos, 90\% deles na rede pública de ensino, ou seja, 10 milhões; 2) uma expansão de EJA-ensino médio que atinja uma matrícula de 5 milhões na rede pública e 3) uma expansão da educação profissional de nível técnico integrado à formação geral, de forma a atingir uma matrícula pública de 1,5 milhões de alunos.

O cenário apresentado significa um salto no padrão de financiamento do ensino médio que predomina hoje no país. Ele viabiliza uma expansão com qualidade e representa cerca de três vezes o valor atualmente destinado ao setor (estimado em $0,9 \%$ do PIB, incluindo os recursos do Sistema S).

Em um cenário em que se vislumbra para o novo PNE 2011-2020 gastos públicos em educação da ordem de $10 \%$ do PIB, os 2,6\% do PIB projetados para o ensino médio integrado são claramente justificáveis, assim como também o é esse índice global destinado à educação em um país que arrecada cerca de 35\% do PIB em tributos. 
De todos os desafios que se colocam para as diferentes etapas de nossa educação, que não são poucos, com certeza, aqueles referentes ao ensino médio são os que demandam respostas mais urgentes, pois precisamos sair da situação de massificação barata. Nossos jovens têm direito a uma educação que lhes faça sentido e ofereça novos horizontes.

\section{Quadro 2}

Estimativa de recursos necessários para um ensino médio de qualidade (valores em R $\$$ de 2010)

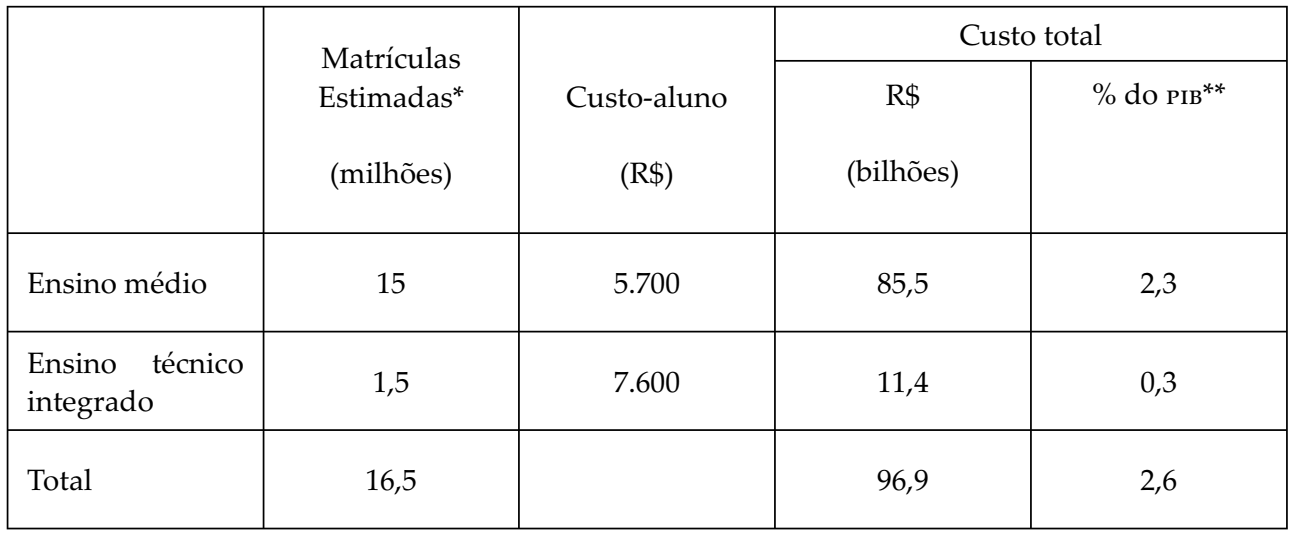

* Regular e EJA

** PIB/2010 considerado de R \$ 3.674.964 mil e PIB per capita considerado de R $\$ 19.016$.

Fonte: Estimativas dos autores.

\section{Notas}

1. Neste trabalho adotou-se o Índice Nacional de Preços ao Consumidor Amplo (IPCA) por ser o índice oficial de inflação.

2. Os dados que propiciaram as análises e projeções que serão feitas neste item foram levantados por Thiago Alves, a partir dos microdados do Censo Escolar de 2010, a quem os autores agradecem.

\section{Referências}

ADRIÃO, T. et al. Uma modalidade peculiar de privatização da educação pública: a aquisição de "sistemas de ensino" por municípios paulistas. Educação E Sociedade, Campinas, v. 30, n. 108, p. 799-818, out. 2009.

ALVES, T.; PINTO, J.M.R. Remuneração e características do trabalho docente no Brasil: um aporte dos dados do censo escolar e da PNAD. Cadernos de Pesquisa, São Paulo, 2011. (no prelo). 
AMARAL, N.C. O financiamento das IFEs brasileiras e o custo do aluno em fHC e Lula. Trabalho aprovado para apresentação na $34^{a}$ Reunião Anual da ANPEd, Natal, 2 a 5 de outubro de 2011. (mimeo.).

ASSOCIAÇÃO NACIONAL DOS DIRIGENTES DAS INSTITUIÇÕES FEDERAIS DE ENSINO SUPERIOR (ANDIFES). Indicadores de desempenho das IFES (1995-2000). Brasília, DF, 2002.

BARBIERI, C. Reforma no Sistema S gera debate acalorado. Folha de S. Paulo, São Paulo, 17 maio 2008. Disponível em: <http://www1.folha.uol.com.br/folha/dinheiro/ ult91u402662.shtml>. Acesso em: 10 jun. 2011.

BRASIL. Constituição (1988). Constituição da República Federativa do Brasil. Diário Oficial da União, Brasília, DF, 5 out. 1988.

BRASIL. Constituições do Brasil: 1934, 1937, 1946 e 1967 e suas alterações. Brasília, DF: Senado Federal, 1986.

BRASIL. Lei n. 5.692, de 11 de agosto de 1971. Fixa as Diretrizes e Bases para o ensino de $1^{\circ}$ e $2^{\circ}$ graus e dá outras providências. Diário Oficial da União, Brasília, DF, 12 ago.1996.

BRASIL. Lei n. 9.394, de 20 de dezembro de 1996. Estabelece as Diretrizes e Bases da Educação Nacional. Diário Oficial da União, Brasília, DF, 23 dez. 1996.

BRASIL. Lei n. 11.494, de 20 de junho de 2007. Regulamenta o Fundo de Manutenção e Desenvolvimento da Educação Básica e de Valorização dos Profissionais da Educação - FUNDEB, de que trata o art. 60 do ADCT e dá outras providências. Diário Oficial da União, Brasília, DF, 21 jun. 2007.

BRASIL. Ministério da Educação. Instituto Nacional de Estudos e Pesquisas Educacionais (INEP). Censo Escolar 2010: microdados. Brasília, DF: MEC/INEP, 2010.

BRASIL. Tribunal de Contas da União. Relatórios anuais de gestão. Disponível em: $<$ http://portal2.tcu.gov.br/portal/page/portal/Tcu/comunidades/contas/relatorio_ gestao/2008>. Acesso em: 20 maio 2011.

DAVIES, N. Os procedimentos adotados pelo tribunal de contas do Piauí para a verificação das receitas e despesas vinculadas à educação. Educação \& Sociedade, Campinas, v. 31, n. 110, p. 93-111, mar. 2010.

MELCHIOR, J.C.A. O financiamento da educação no Brasil. São Paulo: EPU, 1987.

OLIVEIRA, R. Possibilidades do ensino médio integrado diante do financiamento público da educação. Educação \& Pesquisa, São Paulo, v. 35, n.1, p. 51-66, jan.-abr. 2009. 
ORGANISATION FOR ECONOMIC CO-OPERATION AND DEVELOPMENT (OCDE). Education at a Glance 2009: oecD Indicators. Paris, 2009. Disponível em: $<$ http://www.oecd.org/dataoecd/1/42/43658785.pdf>

PINTO, J.M.R. Financiamento do ensino médio no Brasil: uma abordagem inicial. Trabalho, Educação \& Saúde, Rio de Janeiro, v. 2, n. 1, p. 135-151, 2004.

ROMANELLI, O.O. História da Educação no Brasil (1933-1973). Petrópolis: Vozes, 1985.

Recebido em 17 de julho de 2011.

Aprovado em 10 de agosto de 2011. 